\title{
Beneficial Role of Exogenous Spermidine on Nitrogen Metabolism in Tomato Seedlings Exposed to Saline-alkaline Stress
}

\author{
Yi Zhang', Xiao-Hui Hu' ${ }^{1}$ Yu Shi, Zhi-Rong Zou'², Fei Yan, Yan-Yan Zhao, Hao Zhang, \\ and Jiu-Zhou Zhao \\ College of Horticulture, Northwest Agricultural \& Forest University, No. 3 Taicheng Road, Yangling, \\ Shaanxi 712100, People's Republic of China
}

\begin{abstract}
AdDitional INDEX wORDs. ammonium assimilation, glutamate dehydrogenase, glutamine synthetase, glutamate synthase, transamination

Abstract. We studied the effects of exogenous spermidine (Spd) on plant growth and nitrogen metabolism in two cultivars of tomato (Solanum lycopersicum) that have differential sensitivity to mixed salinity-alkalinity stress: 'Jinpeng Chaoguan' (salt-tolerant) and 'Zhongza No. 9' (salt-sensitive). Seedling growth of both tomato cultivars was inhibited by salinity-alkalinity stress, but Spd treatment alleviated the growth reduction to some extent, especially in 'Zhongza No. 9'. Exogenous Spd may help reduce stress-induced increases in free amino acids, ammonium $\left(\mathrm{NH}_{4}^{+}\right)$ contents, and NADH-dependent glutamate dehydrogenase (NADH-GDH) activities; depress stress-induced decreases in soluble protein and nitrate content; and depress nitrate reductase, nitrite reductase, glutamine synthetase (GS), NADH-dependent glutamate synthase (NADH-GOGAT), glutamate oxaloacetate transaminase (GOT), and glutamate pyruvate transaminase (GPT) activities, especially for 'Zhongza No. 9'. Based on our results, we suggest that exogenous Spd promotes the assimilation of excess toxic $\mathrm{NH}_{4}{ }^{+}$by coordinating and strengthening the synergistic action of NADH-GDH, GS/NADH-GOGAT, and transamination pathways, all during saline-alkaline stress. Subsequently, $\mathrm{NH}_{4}{ }^{+}$and its related enzymes (GDH, GS, GOGAT, GOT, and GPT), in vivo, are maintained in a proper and balanced state to enable mitigation of stress-resulted damages. These results suggest that exogenous Spd treatment can relieve nitrogen metabolic disturbances caused by salinity-alkalinity stress and eventually promote plant growth.
\end{abstract}

\begin{abstract}
Salinity-alkalinity mixed stress is becoming one of the most serious environmental restrictions on plant production. It causes intracellular ionic imbalance, low osmotic potential $\left(\psi_{\mathrm{S}}\right)$, membrane dysfunction, attenuation of metabolic activity, and secondary effects that result in growth inhibition and sometimes cell death (Li et al., 2010a). Tomato was chosen for this study because its importance is increasing worldwide, it is considered a moderately salt-tolerant crop, and it has considerable cultivar differences (Galvez et al., 2012). Throughout evolution, plants have acquired an array of physiological and biochemical regulatory mechanisms to survive under salt stress such as the accumulation of compatible solutes and the maintenance of nitrogen balance (Debouba et al., 2006; Li et al., 2010a). In addition, research has developed many measures to solve this problem, including the application of exogenous substances such as polyamines among others (Hu et al., 2012; Roychoudhury et al., 2011). Alkaline salt stress and neutral salt stress are two distinct types of stresses on plants and are referred to as "alkali stress" and "salt stress," respectively. Alkaline salts $\left(\mathrm{NaHCO}_{3}\right.$ and $\left.\mathrm{Na}_{2} \mathrm{CO}_{3}\right)$ can induce much stronger destructive effects on plants than neutral salts $\left(\mathrm{NaCl}\right.$ and $\left.\mathrm{Na}_{2} \mathrm{SO} 4\right)(\mathrm{Hu}$ et al., 2012). Numerous studies have clearly shown that the
\end{abstract}

Received for publication 25 Sept. 2012. Accepted for publication 6 Nov. 2012. This work was supported by grants from the National Natural Science Foundation of China (No. 31101581), the National Key Technology R\&D Program of China (No. 2011BAD12B03-03), and China Agriculture Research System (No. CARS-25-D-02).

${ }^{1}$ The fist two authors (Y.Z. and X.-H.H.) contributed equally to this work and should be considered co-first authors.

${ }^{2}$ Corresponding author. E-mail: zouzhirong2005@hotmail.com. effects from salinity-alkalinity stress are more severe than those from neutral salt stress, mainly as a result of the higher $\mathrm{pH}$ value (Hu et al., 2012). Despite those findings, little work has been done to study salinity-alkalinity stress despite considerable research on neutral salt tolerance in tomato (Galvez et al., 2012; Zushi and Matsuzoe, 2009). Further study of the problems with salinity-alkalinity stress as well as those from neutral salt stress is, therefore, profoundly important.

Polyamines are low-molecular-weight aliphatic amines that are believed to have important functions in a wide range of processes such as in promotion of growth, cell division, DNA replication, and protein synthesis (Roychoudhury et al., 2011). In plants, spermidine and spermine (Spm), and their precursor, putrescine (Put), are the major polyamines, acting as second messengers that mediate responses to various kinds of environmental stressors, including osmotic stressors, salinity changes, drought, ozone, heavy metals, ultraviolet, and so on (Alcazar et al., 2006; Groppa and Benavides, 2008). Despite a close correlation between abiotic stress intensity and polyamine levels in plants, the specific regulation mechanism of polyamines is still obscure and very controversial. Some studies have suggested that exogenous polyamines could help enhance salt tolerance of crops and eventually improve their productivity under high salinity (Chattopadhayay et al., 2002). Accumulation of endogenous Put usually militates against growth of plants and can even increase the deleterious effects of salt stress, yet the protective roles of higher endogenous Spd and Spm against salt stress are well documented for some plants (Duan et al., 2008; Roychoudhury et al., 2011). Compared with other type of polyamine, Spd could more effectively alleviate 
the adverse impacts of salinity-alkalinity (Hu et al., 2012). We, therefore, explored the inherent regulative mechanisms of exogenous Spd so as to enrich the theoretical foundations of stress resistance in tomato.

Nitrogen is required in great quantities by plants because it is an essential macronutrient involved in the biochemistry of coenzymes, polyamines, photosynthetic pigments, and secondary metabolites (Maathuis, 2009). Despite the existence of several forms of nitrogen $(\mathrm{N})$, nitrate $\left(\mathrm{NO}_{3}{ }^{-}\right)$is the most bioavailable and most assimilated by plants. $\mathrm{NO}_{3}{ }^{-}$must be reduced to nitrite $\left(\mathrm{NO}_{2}^{-}\right)$and then converted into $\mathrm{NH}_{4}{ }^{+}$by the successive action of nitrate reductase (NR) and nitrite reductase (NiR) (Gangwar and Singh, 2011). $\mathrm{NH}_{4}{ }^{+}$is toxic to the cell and needs to be rapidly incorporated into organic compounds such as amino acids, proteins, and other cellular compositions necessary for plant growth and development (Zhang et al., 2006). This process is mainly carried out by the synergistic action of GDH, GS, GOGAT, GOT, and GPT (Debouba et al., 2006; Liang et al., 2011). Many studies have shown that these $\mathrm{N}$ metabolism enzymes respond differently depending on species, cultivar, tissue, and duration and intensity of stress (Gangwar and Singh, 2011; Liang et al., 2011; Ramanjulu et al., 1994; Wang et al., 2007; Zhang et al., 2006). Despite accumulating research that has enriched our understanding of $\mathrm{N}$ metabolism in plant, less is known about the influence of exogenous Spd treatment on $\mathrm{N}$ metabolism in tomato seedlings that have salinity-alkalinity stress.

To address this, one must study the inner mechanisms of exogenous Spd that are responsible for regulating tomato tolerance to complex neutral and alkaline salt stress. Such information may help determine how the application of exogenous Spd protects plants against serious stress injuries. Our focus in this study, therefore, was to investigate whether foliar-sprayed Spd enhances saline-alkaline stress resistance in tomato seedlings, whether the effect is related to $\mathrm{N}$ metabolism, and how the $\mathrm{N}$ mechanisms of the two cultivars differ from each other.

\section{Materials and Methods}

Plant materials and treatments. All experiments were done from 10 Mar. 2011 to 26 Oct. 2011.

Two tomato cultivars were used in the study: 'Jinpeng Chaoguan', a highly salt-tolerant ecotype, and 'Zhongza No. 9', a more salt-sensitive ecotype (Hu et al., 2012). We sterilized 300 seeds of each cultivar, immersed them in distilled water for $6 \mathrm{~h}$, and germinated them at $26{ }^{\circ} \mathrm{C}$ in dark. After $3 \mathrm{~d}$, the germinated seeds were sown and placed in a special seedling greenhouse with an average temperature of $26 / 18^{\circ} \mathrm{C}$ (day/night), a 16-h light $\left(800 \mu \mathrm{mol} \cdot \mathrm{m}^{-2} \cdot \mathrm{s}^{-1}\right)$ and 8 -h dark photoperiod, and a relative humidity of $50 \%$ to $90 \%$.

When the third leaves were fully expanded, all seedlings were transplanted into rectangular hydroponic containers containing half-strength Hoagland nutrient solution. The nutrient solution was replaced every 4 to $5 \mathrm{~d}$, and the air pipelines were regularly serviced to ensure regular supply of dissolved oxygen. When the sixth leaves were expanded, we separated out 240 seedlings of each cultivar into each of the following four treatments: 1) $\mathrm{CT}=$ in half-strength Hoagland solution; 2) $\mathrm{M}=$ in $75 \mathrm{~mm}$ saline-alkaline solution $\left(\mathrm{NaCl}: \mathrm{Na}_{2} \mathrm{SO}_{4}: \mathrm{NaHCO}_{3}\right.$ : $\mathrm{Na}_{2} \mathrm{CO}_{3}=1: 9: 9: 1$, molar ratio) (Hu et al., 2012);3) $\mathrm{S}=$ sprayed with $0.25 \mathrm{~mm}$ Spd (Sigma-Aldrich, St. Louis, MO) and in halfstrength Hoagland solution; and 4) MS = sprayed with $0.25 \mathrm{~mm}$ Spd and in $75 \mathrm{~mm}$ saline-alkaline solution. For experimental 
purposes, the $75 \mathrm{~mm}$ saline-alkaline solution had a higher $\mathrm{pH}$ (8.55) and electrical conductivity (EC) value $\left(4726 \mu \mathrm{S} \cdot \mathrm{cm}^{-1}\right)$, whereas the non-saline-alkaline solution had a lower $\mathrm{pH}(6.40)$ and EC value $\left(1158 \mu \mathrm{S} \cdot \mathrm{cm}^{-1}\right)$. At 1800 to $1830 \mathrm{HR}$, each day, both surfaces of all tomato leaves were sprayed with either $0.25 \mathrm{~mm}$ Spd or water, gently and uniformly, until a water fog film was formed on the leaf. The experimental design applied four treatments to each cultivar, totaling eight treatments, with three replicates per treatment.

The sixth and seventh leaves (excluding petioles), and the roots, were collected on Days $0,2,4,6$, and 8 after treatment. All the samples were flash frozen in liquid $\mathrm{N}$ before storing at $-80{ }^{\circ} \mathrm{C}$ for separate biochemical analyses.

Plant growth analysis. Ten seedlings of each treatment were randomly selected $8 \mathrm{~d}$ after treatment. Plant heights and stem diameters were measured three times. To determine fresh weight of the different parts, each plant was divided into aboveand belowground parts and weighed, respectively. The dry weight of a sample was obtained by drying material in an oven at $105^{\circ} \mathrm{C}$ for $15 \mathrm{~min}$ and then at $75^{\circ} \mathrm{C}$ for $72 \mathrm{~h}$. Relative growth rate (RGR) was determined by: $\mathrm{RGR}=[\ln$ (final biomass) $-\ln$ (initial biomass)]/(duration of treatment days) (Kingsbury et al., 1984).

Analyses of soluble protein and free Amino ACID CONTENTS. We homogenized $500 \mathrm{mg}$ each of frozen root and leaf in a $50 \mathrm{~mm}$ cold K-P buffer, at $\mathrm{pH} 7.0$, and centrifuged at $12,000 g_{\mathrm{n}}$ for $15 \mathrm{~min}$ at $4{ }^{\circ} \mathrm{C}$ in a refrigerated high-speed centrifuge (Biofuge Stratos, Osterode, Germany). The resulting supernatant was used for determination of soluble protein by the Coomassie blue staining method with a bovine serum albumin standard (Bradford, 1976). Free amino acid content was estimated with the ninhydrin method (Yemm and Cocking, 1955).

Analyses of $\mathrm{NO}_{3}^{--}$AND $\mathrm{NH}_{4}{ }^{+}-\mathrm{N}$ LeVELS. Root and leaf samples, from control and treated seedlings, were dried at $75{ }^{\circ} \mathrm{C}$ until constant weight was obtained. The dried material (200 mg) was ground to a powder and extracted in $10 \mathrm{~mL}$ of distilled water for $2.5 \mathrm{~h}$. The $\mathrm{NO}_{3}{ }^{-}-\mathrm{N}$ content was determined by mixing $0.2 \mathrm{~mL}$ extracted solution with $10 \%(\mathrm{w} / \mathrm{v})$ salicylic acid, in sulfuric acid, at $96 \%$, and the final $\mathrm{NO}_{3}{ }^{-}$concentration was measured by spectrophotometry with respect to its standard curve (Cataldo et al., 1975). The $\mathrm{NH}_{4}{ }^{+}-\mathrm{N}$ content was determined with the colorimetric assay (Krom, 1980).

Extractions AND ASSAYS OF NITROGEN METABOLISM ENZYMES. Homogenate and centrifugation operations were performed at $4{ }^{\circ} \mathrm{C}$. The protein concentrations of the extracts were determined according to the methods of Bradford (1976).

Nitrate Reductase AND NitRite REDUCTASE ENZYME ACTIVITY ASSAY. NR and NiR activities were estimated according to the methods of Gangwar and Singh (2011). Fresh leaf and root (500 mg each) were homogenized in $100 \mathrm{~mm}$, K-P buffer (pH 7.5), containing $2 \mathrm{~mm}$ EDTA, $5 \mathrm{~mm}$ cysteine, $2 \mathrm{~mm}$ dithiothreitol, and $0.5 \%(\mathrm{w} / \mathrm{v})$ polyvinylpolypyrrolidone (Sangon Biotech, Shanghai, China) and using a pre-cooled mortar and pestle. The homogenate was centrifuged at 20,000 $g_{n}$ for $20 \mathrm{~min}$, and the supernatant was used to determine NR and NiR activities. The amount of formed or reduced $\mathrm{NO}_{2}^{-}$was calculated using a standard curve prepared with $\mathrm{NaNO}_{2}$. One unit of NR or NiR activity was defined as $1 \mathrm{nmol}$ of formed or reduced $\mathrm{NO}_{2}^{-}$per milligram protein per hour, respectively.

NADH-DEPENDENT GLUTAMATE DEHYDROGENASE ENZYME ACTIVITY ASSAY. GDH activity was measured by monitoring the oxidation of NADH at $340 \mathrm{~nm}$ (Gangwar and Singh, 2011). Two controls, without ketoglutarate and $\left(\mathrm{NH}_{4}\right)_{2} \mathrm{SO}_{4}$, respectively, were used to correct endogenous NADH oxidation. The decrease in absorbance was recorded for $5 \mathrm{~min}$. One unit of GDH activity was defined as $1 \mathrm{nmol}$ of oxidized NADH per milligram protein per minute.

Glutamine Synthetase and NAPH-dePendent GLUTAMATE SYNTHASE ENZYME ACTIVITY ASSAYS. GOGAT activity was measured with the colorimetric assay (Gangwar and Singh, 2011). Decreases in absorbance were read at $340 \mathrm{~nm}$ for $5 \mathrm{~min}$, and GOGAT activity was calculated and defined as GDH enzyme.

GS activity was measured using an adaptation of Lillo's (1984) method. Absorbance of reaction mixture was read at $540 \mathrm{~nm}$. GS activity was calculated using a standard curve prepared with $\gamma$-glutamylhydroxamate (Sigma-Aldrich). One unit of GS activity was defined as $1 \mathrm{nmol}$ of formed $\gamma$-glutamylhydroxamate per milligram protein per minute.

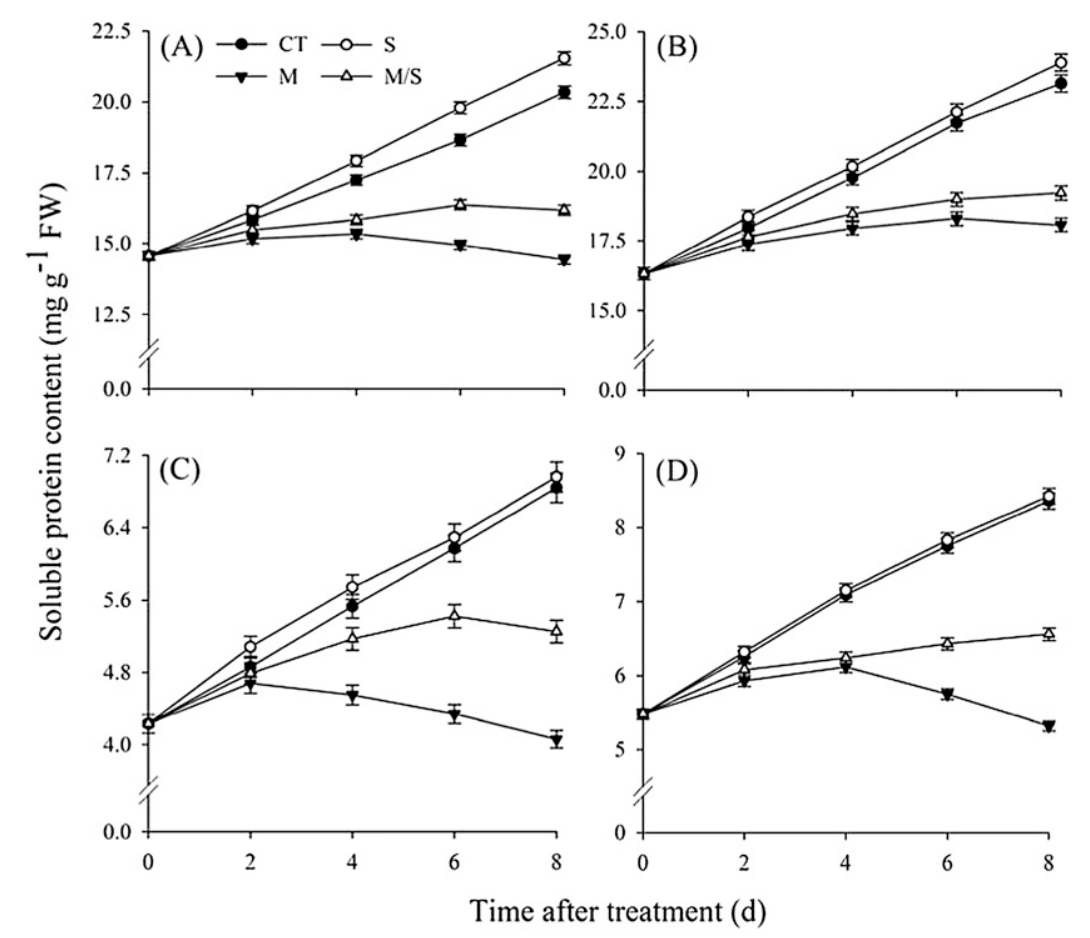

Fig. 1. Effects of exogenous spermidine on soluble protein contents of tomato seedlings grown under salinityalkalinity combined stress: (A) 'Zhongza No. 9' leaves, (B) 'Jinpeng Chaoguan' leaves, (C) 'Zhongza No. 9' roots, (D) 'Jinpeng Chaoguan' roots. Data represent means \pm SE; the vertical bars are the $\mathrm{SES}(\mathrm{n}=3)$; CT $=$ in halfstrength $(1 / 2)$ Hoagland solution, $\mathrm{M}=$ in $75 \mathrm{~mm}$ saline-alkaline solution $\left(1 \mathrm{NaCl}: 9 \mathrm{Na}_{2} \mathrm{SO}_{4}: 9 \mathrm{NaHCO}_{3}: 1\right.$ $\mathrm{Na}_{2} \mathrm{CO}_{3}$ ), $\mathrm{S}=$ sprayed with $0.25 \mathrm{~mm}$ spermidine and in $1 / 2$ Hoagland solution, $\mathrm{M} / \mathrm{S}=$ sprayed with $0.25 \mathrm{~mm}$ spermidine and in $75 \mathrm{~mm}$ saline-alkaline solution. 
GLUTAMATE OXAlOACETATE TRANSAMINASE AND GLUTAMATE PYRUVATE TRANSAMINASE ENZYME ACTIVITY ASSAYS. The activities of GOT and GPT were measured with the method described by Liang et al. (2011). The assays contained either aspartic acid or alanine, for GOT and GPT, respectively. Enzyme activities were calculated by measuring their absorbance changes at $500 \mathrm{~nm}$. Controls were conducted the same way but with inactivated enzymes. GOT and GPT activities were calculated using a standard curve prepared with pyruvic acid. One unit of enzyme was defined as $1 \mu \mathrm{mol}$ of formed pyruvic acid per gram fresh weight for $30 \mathrm{~min}$ under assay conditions.

STATistical AnAlysis. Growth was measured from 10 replicates, whereas all other experiments were performed in triplicate. Data were statistically analyzed with SAS software (Version 8.1; SAS Institute, Cary, NC) using Duncan's multiple range test at the 0.05 level. A significant difference of the same index was represented by different lower case letters. The SEs of the means were also calculated and presented in the graphs as error bars.

\section{Results}

GrowTH RESPONSES. The dry weights of shoots and roots and the root/shoot dry weight ratio (Table 1) of tomato seedlings were significantly reduced after $8 \mathrm{~d}$ of salinity-alkalinity treatment as compared with the control $(P<0.05)$. This effect was greater in 'Zhongza No. 9' (43\%, 60\%, and 30\%, respectively) than in 'Jinpeng Chaoguan' plants $(18 \%, 34 \%$, and $18 \%$, respectively). Under non-stress conditions, exogenous Spd exerted no significant effect on either cultivar. Spd treatment alleviated the salinityalkalinity-induced growth reduction to some extent in both cultivars, but more so in 'Zhongza No. 9': after 8 d of stress, the Spd treatment enhanced the plant height of 'Zhongza No. 9' and 'Jinpeng Chaoguan' by $10 \%$ and $1 \%$, respectively. A similar increase in stem diameter occurred: $6 \%$ in 'Zhongza No. 9' and $2 \%$ in 'Jinpeng Chaoguan'. These indices showed that salinity-alkalinity stress noticeably inhibits the growth of both tomato varieties and that treating with Spd could mitigate seedling injuries to a certain degree, especially in 'Zhongza No. 9'.

SOLUbLE PROTEIN AND FREE AMino ACID Contents. Salinityalkalinity stress significantly reduced soluble protein content $(P<0.05)$ as compared with the control (Fig. 1). Overall, 'Zhongza No. 9' showed more sensitivity to stress and Spd despite it having lower protein levels than 'Jinpeng Chaoguan'. In comparison with the treatment of mixed stress, Spd caused significant increases in protein contents at all stressed times $(P<0.05)$. Furthermore, the soluble protein contents of both cultivars were higher in leaves than in roots.

Similar to the soluble protein content, free amino acid levels of both cultivars were higher in leaves than in roots, and 'Jinpeng Chaoguan' accumulated more free amino acids than 'Zhongza No. 9' (Fig. 2). No significant differences, across all treatments, occurred in the leaves of each cultivar $(P<0.05)$. As for roots, under salinity-alkalinity stress, the free amino acid levels of both cultivars showed similar changes, rising early but declining later. Maximum levels in stressed root of 'Zhongza No. 9' occurred on Day 4, whereas the peak value was postponed to Day 6 with application of Spd. Nevertheless, exogenous Spd had little impact on the peak time of free amino acids in 'Jinpeng Chaoguan' roots, and the maximum occurred on Day 6 after treatment.

Concentrations of $\mathrm{NO}_{3}{ }^{-}-\mathrm{N}$ and $\mathrm{NH}_{4}{ }^{+}-\mathrm{N}$. $\mathrm{NO}_{3}{ }^{-}-\mathrm{N}$ results show that leaf and root had similar trends under the same conditions (Fig. 3). Under salinity-alkalinity stress, $\mathrm{NO}_{3}{ }^{-} \mathrm{N}$ content in both cultivars decreased during the early period and then rose. Meanwhile, the $\mathrm{NO}_{3}{ }^{-} \mathrm{N}$ levels in leaves and roots were reduced to minimums on either Day 2 or 4 after treatment, respectively. The $\mathrm{NO}_{3}{ }^{-} \mathrm{N}$ contents in no-stress plants were slightly elevated by exogenous Spd. For the saline-alkalinestressed plants, their leaf and root $\mathrm{NO}_{3}{ }^{-} \mathrm{N}$ levels were significantly promoted by $\mathrm{Spd}(P<0.05)$. In addition, leaf $\mathrm{NO}_{3}{ }^{-} \mathrm{-N}$ contents of both cultivars were lower than their roots, and 'Jinpeng Chaoguan' had higher $\mathrm{NO}_{3}{ }^{-} \mathrm{N}$ levels than 'Zhongza No. 9' despite being under the same treatment.

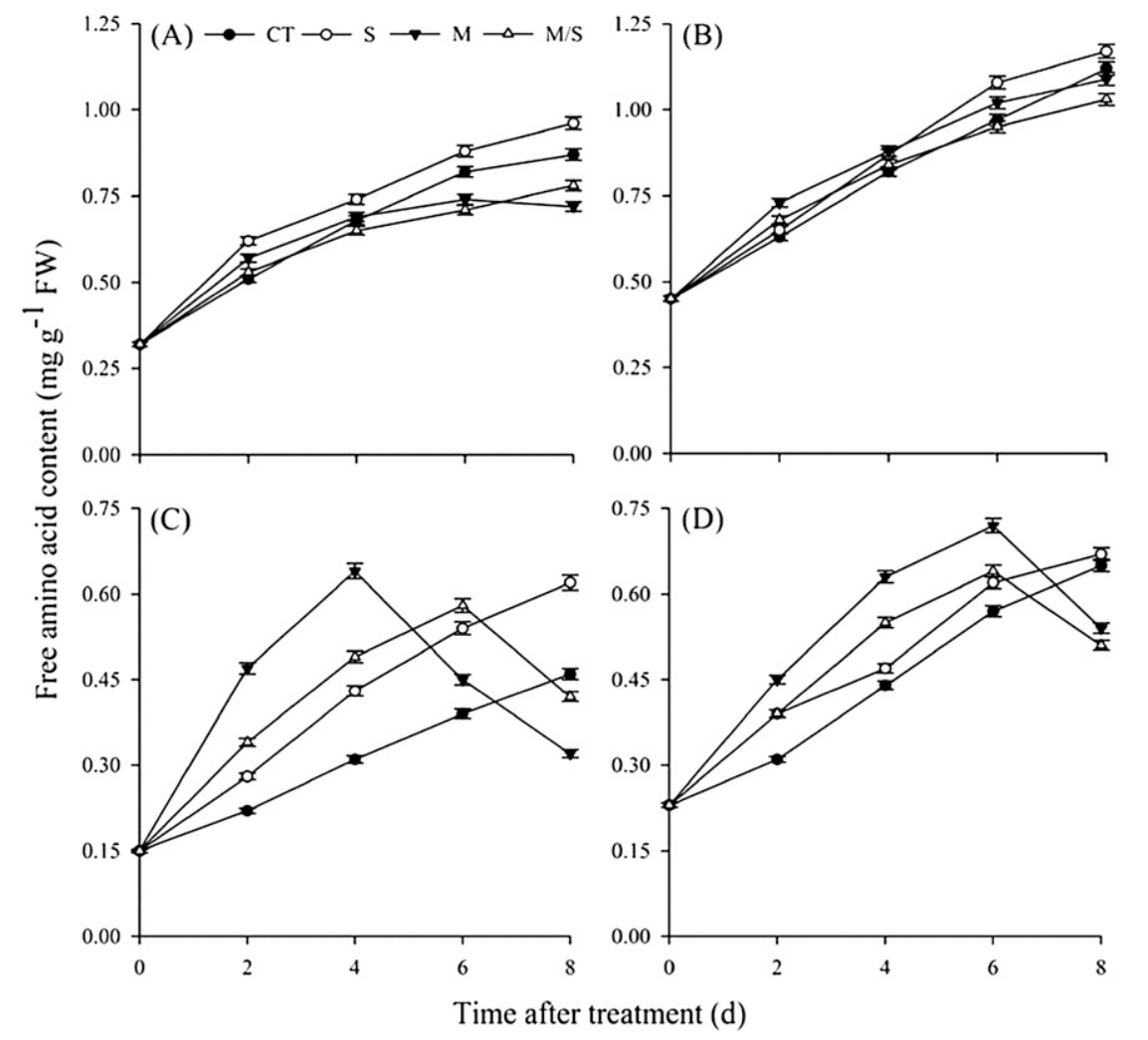

Fig. 2. Effects of exogenous spermidine on free amino acid contents of tomato seedlings grown under salinityalkalinity combined stress: (A) 'Zhongza No. 9' leaves, (B) 'Jinpeng Chaoguan' leaves, (C) 'Zhongza No. 9' roots, (D) 'Jinpeng Chaoguan' roots. Data represent means \pm SE; the vertical bars are the SES $(n=3)$; $\mathrm{CT}=$ in halfstrength $(1 / 2)$ Hoagland solution, $\mathrm{M}=$ in $75 \mathrm{~mm}$ saline-alkaline solution $\left(1 \mathrm{NaCl}: 9 \mathrm{Na}_{2} \mathrm{SO}_{4}: 9 \mathrm{NaHCO}_{3}: 1\right.$ $\mathrm{Na}_{2} \mathrm{CO}_{3}$ ), $\mathrm{S}=$ sprayed with $0.25 \mathrm{~mm}$ spermidine and in $1 / 2$ Hoagland solution, $\mathrm{M} / \mathrm{S}=$ sprayed with $0.25 \mathrm{~mm}$ spermidine and in 75 mм saline-alkaline solution. 


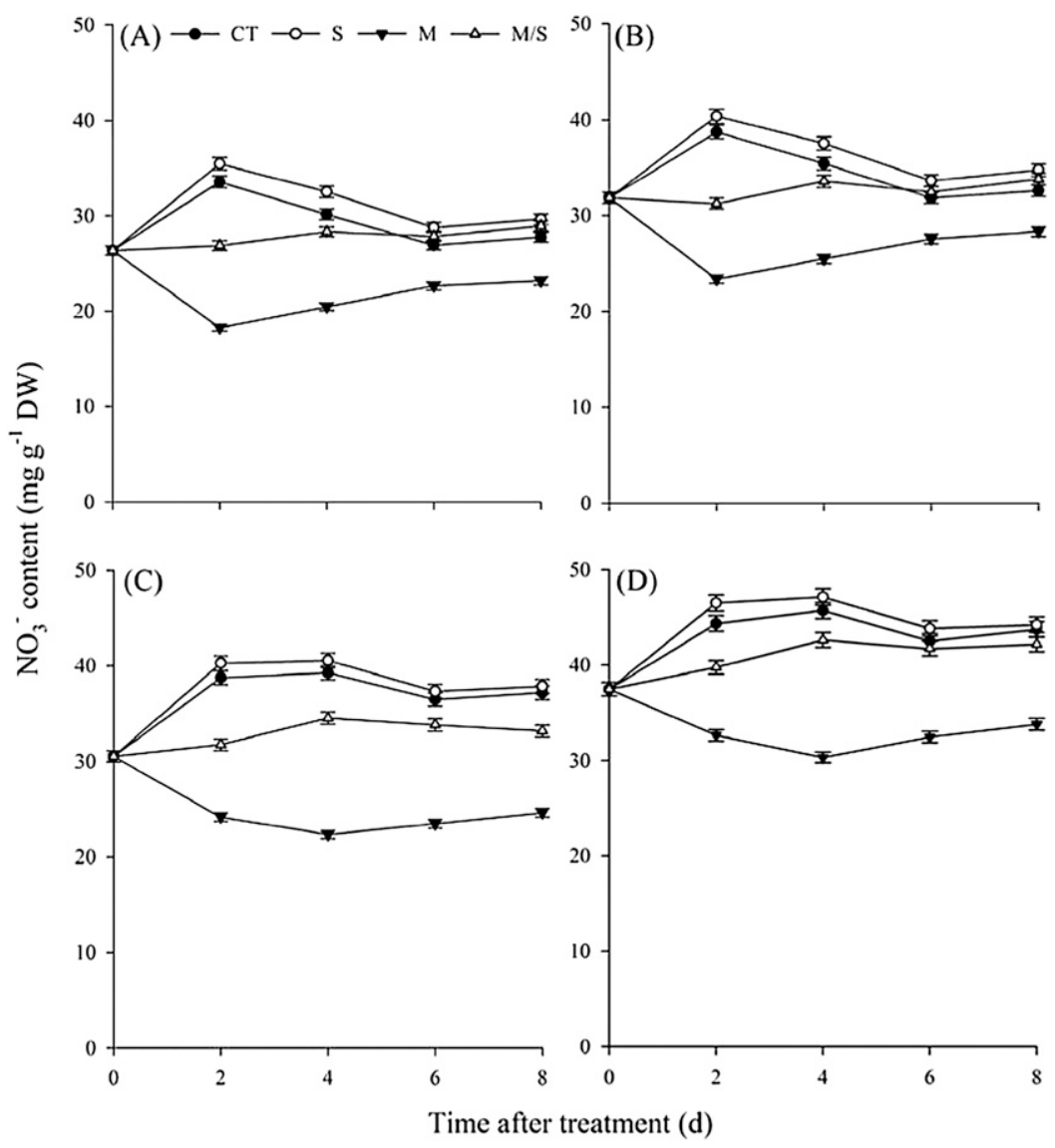

Fig. 3. Effects of exogenous spermidine on nitrate nitrogen $\left(\mathrm{NO}_{3}{ }^{-}-\mathrm{N}\right)$ levels of tomato seedlings grown under salinity-alkalinity combined stress: (A) 'Zhongza No. 9' leaves, (B) 'Jinpeng Chaoguan' leaves, (C) 'Zhongza No. 9' roots, (D) 'Jinpeng Chaoguan' roots. Data represent means $\pm \mathrm{SE}$; the vertical bars are the SES (n=3); CT = in half-strength (1/2) Hoagland solution, $\mathrm{M}=$ in $75 \mathrm{~mm}$ saline-alkaline solution $\left(1 \mathrm{NaCl}: 9 \mathrm{Na}_{2} \mathrm{SO}_{4}: 9 \mathrm{NaHCO}_{3}: 1\right.$ $\mathrm{Na}_{2} \mathrm{CO}_{3}$ ), $\mathrm{S}=$ sprayed with $0.25 \mathrm{~mm}$ spermidine and in $1 / 2$ Hoagland solution, $\mathrm{M} / \mathrm{S}=$ sprayed with $0.25 \mathrm{~mm}$ spermidine and in $75 \mathrm{~mm}$ saline-alkaline solution.

$\mathrm{NH}_{4}{ }^{+}-\mathrm{N}$ in the leaves of 'Zhongza No. 9' was significantly higher than that in 'Jinpeng Chaoguan' leaves $(P<0.05)$ under salinity-alkalinity stress. Although $\mathrm{NH}_{4}{ }^{+}-\mathrm{N}$ in leaves and roots increased early and declined later, the leaf peak value occurred on Day 4 after treatment and root peak value occurred on Day 2, all under salinity-alkalinity stress. Overall, 'Zhongza No. 9' showed more sensitivity to both salinity-alkalinity stress and exogenous Spd; however, no significant differences in the $\mathrm{NH}_{4}^{+}-\mathrm{N}$ content of 'Jinpeng Chaoguan' seedlings occurred between treatments either with or without exogenous Spd (Fig. 4).

ACTIVITIES OF NITRATE REDUCTASE AND NITRITE REDUCTASE. Under salinity-alkalinity stress, NR activities initially decreased in leaves of both cultivars, but increased on Days 2 and 4, for 'Jinpeng Chaoguan' and 'Zhongza No. 9', respectively (Fig. 5). Leaf NR activity in plants applied with Spd was significantly higher than that of stressed plants $(P<0.05)$, especially in 'Zhongza No. 9'. Similarly, in roots, NR activity initially declined under salinity-alkalinity stress, but then changed little over the remaining days. Compared with the control, exogenous Spd effectively accelerated root NR activity of 'Zhongza No. 9', whereas there was no significant effect on 'Jinpeng Chaoguan' $(P<0.05)$. However, Spd had obvious and positive effects on NR activity of 'Jinpeng Chaoguan' root under the salinity-alkalinity-stressed condition.
In leaves, salinity-alkalinity stress caused a reduction in the NiR activity of both cultivars on Day 2, but a gradual increase occurred both in 'Zhongza No. 9' and 'Jinpeng Chaoguan' over the next 6 or $4 \mathrm{~d}$, respectively. Spd significantly promoted NiR activity in stressed leaves of 'Zhongza No. 9', especially on Days 2 and 4. Compared with the control, Spd had relatively little effect on leaf NiR activity of 'Jinpeng Chaoguan' despite causing a significant increase in 'Zhongza No. 9' $(P<0.05)$. For roots with salinity-alkalinity stress, the NiR activities of both cultivars fell sharply after a slight drop, and Spd significantly promoted NiR activity in 'Zhongza No. 9', yet not in 'Jinpeng Chaoguan'. In contrast to the control, Spd significantly increased NiR activity of both tomato cultivars $(P<0.05)$ with 'Zhongza No. 9' displaying the larger amplitude (Fig. 6). Throughout the whole process and under the same treatments, leaf NR and NiR activities of both cultivars were higher than those of the root, and the NR and NiR activities of 'Zhongza No. 9' were lower than those of 'Jinpeng Chaoguan'.

ACTIVITIES OF NADH-DEPENDENT GLUTAMATE DEHYDROGENASE. In leaves, salinity-alkalinity treatments significantly increased NADH-GDH activities in both tomato varieties $(P<0.05)$, but application of Spd significantly inhibited this enzyme activity, especially in 'Zhongza No. 9' (Fig. 7). Moreover, supply of Spd to unstressed leaves had relatively less influence on NADH-GDH. Except for the individual stress treatment on 'Zhongza No. 9', all treatments had similar trends of rising early, but declining later, with peak values occurring on Day 4. For 'Jinpeng Chaoguan' root, we found no distinct differences in NADH-GDH activity of stressed plants either supplemented with or without Spd as well as between control and individual Spd-sprayed plants. Each treatment on 'Zhongza No. 9' roots also showed a similar trend in NADH-GDH activity. In addition, exogenous Spd had a more prominent facilitative effect on the root NADH-GDH activities of 'Zhongza No. 9' than those of 'Jinpeng Chaoguan'. Finally, root NADH-GDH activity of both cultivars was higher than that of leaf under the same conditions.

ACTIVITIES OF GLUTAMINE SYNTHETASE AND NADH-DEPENDENT GLUTAMATE SYNTHASE. Exogenous Spd did not have any significant influence on the leaf GS activities of normal 'Jinpeng Chaoguan' plants despite it notably boosted the corresponding enzyme activity in stressed plants $[P<0.05$ (Fig. 8)]. Similarly with 'Jinpeng Chaoguan', salinity-alkalinity stress also markedly reduced leaf GS activity in 'Zhongza No. 9' $(P<$ $0.05)$, whereas Spd significantly promoted the homologous enzyme activity in control and stressed plants. In roots of both 


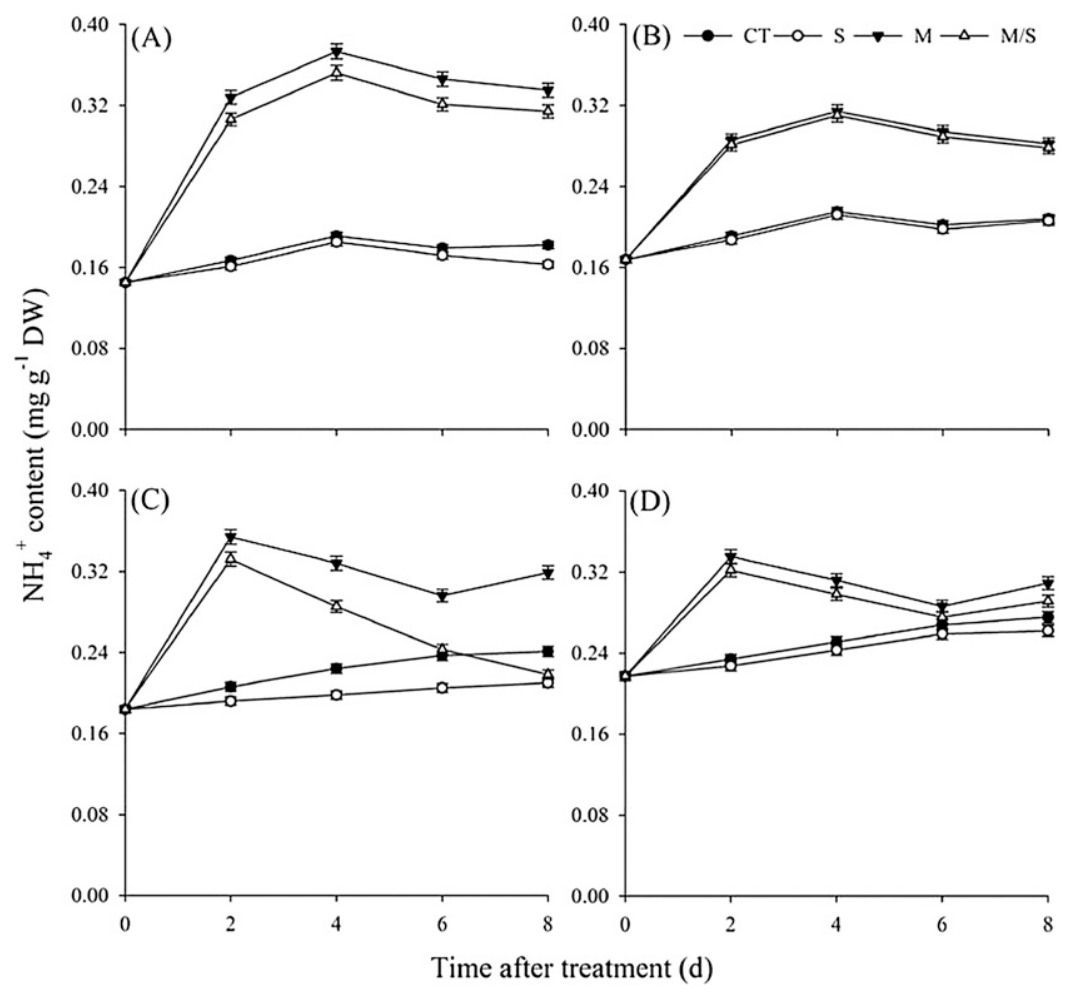

Fig. 4. Effects of exogenous spermidine on ammonium nitrogen $\left(\mathrm{NH}_{4}{ }^{+} \mathrm{-N}\right)$ levels of tomato seedlings grown under salinityalkalinity combined stress: (A) 'Zhongza No. 9' leaves, (B) 'Jinpeng Chaoguan' leaves, (C) 'Zhongza No. 9' roots, (D) 'Jinpeng Chaoguan' roots. Data represent means $\pm \mathrm{SE}$; the vertical bars are the SES $(n=3)$; CT $=$ in half-strength $(1 / 2)$ Hoagland solution, $\mathrm{M}=$ in $75 \mathrm{~mm}$ saline-alkaline solution (1 $\left.\mathrm{NaCl}: 9 \mathrm{Na}_{2} \mathrm{SO}_{4}: 9 \quad \mathrm{NaHCO}_{3}: 1 \quad \mathrm{Na}_{2} \mathrm{CO}_{3}\right), \mathrm{S}=$ sprayed with $0.25 \mathrm{~mm}$ spermidine and in $1 / 2$ Hoagland solution, $\mathrm{M} / \mathrm{S}=$ sprayed with $0.25 \mathrm{~mm}$ spermidine and in $75 \mathrm{~mm}$ saline-alkaline solution.

cultivars, individual Spd treatments exhibited higher GS activities than other treatments, and significant differences $(P<0.05)$ were found between any two treatments of both activities were significantly lower in stressed roots than in normal roots $(P<0.05)$. Moreover, except for the root GS activity in the individual Spd treatment, 'Jinpeng Chaoguan' cultivars. During the salinity-alkalinity stress period, GS showed a higher enzyme activity than 'Zhongza No. 9' under

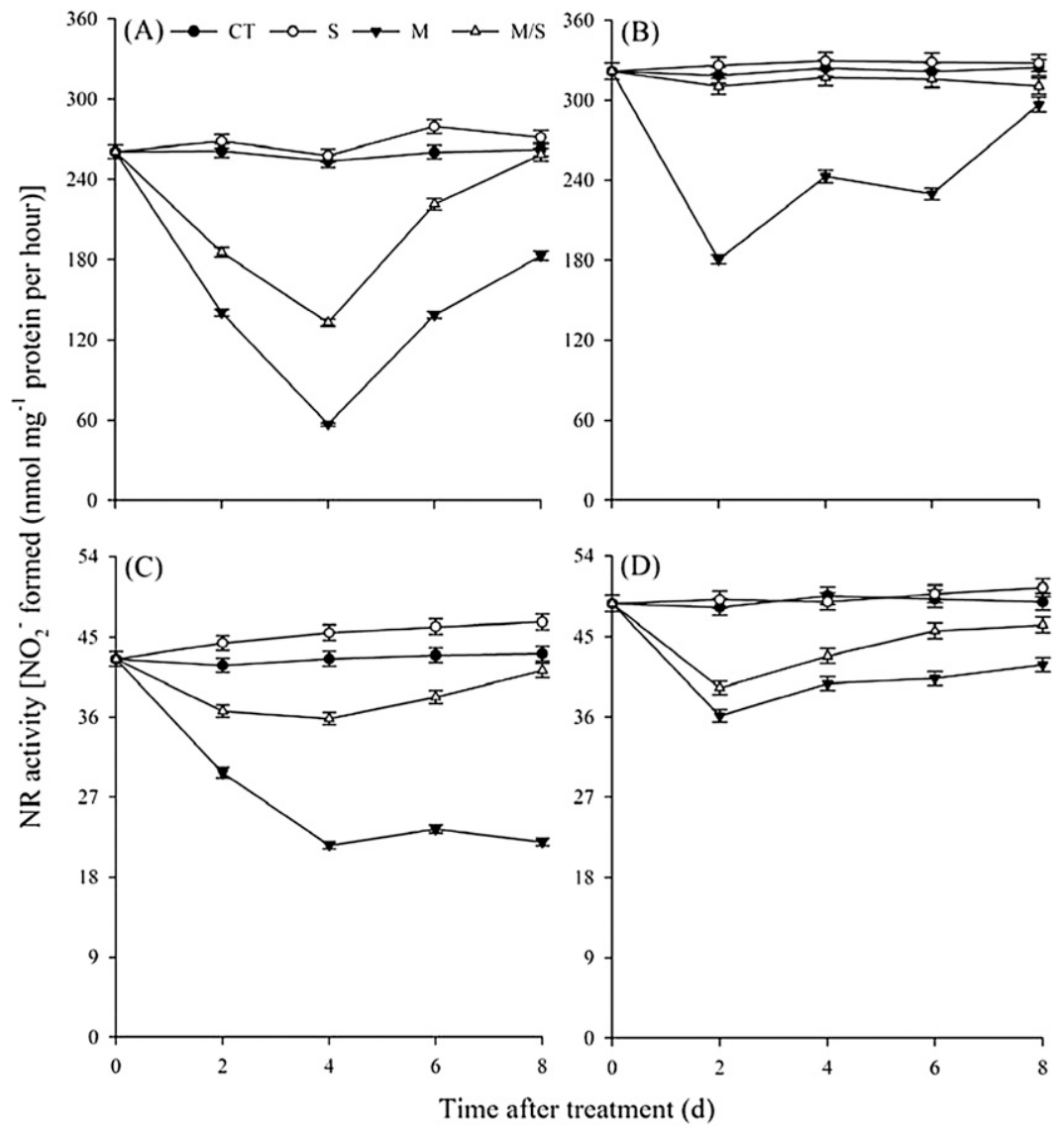

Fig. 5. Effects of exogenous spermidine on nitrate reductase (NR) activities of tomato seedlings grown under salinityalkalinity combined stress: (A) 'Zhongza No. 9' leaves, (B) 'Jinpeng Chaoguan' leaves, (C) 'Zhongza No. 9' roots, (D) 'Jinpeng Chaoguan' roots. Data represent means $\pm \mathrm{SE}$; the vertical bars are the SES $(n=3) ; C T=$ in half-strength $(1 / 2)$ Hoagland solution, $\mathrm{M}=$ in $75 \mathrm{~mm}$ saline-alkaline solution (1 $\left.\mathrm{NaCl}: 9 \mathrm{Na}_{2} \mathrm{SO}_{4}: 9 \mathrm{NaHCO}_{3}: 1 \quad \mathrm{Na}_{2} \mathrm{CO}_{3}\right), \mathrm{S}=$ sprayed with $0.25 \mathrm{~mm}$ spermidine and in $1 / 2$ Hoagland solution, $\mathrm{M} / \mathrm{S}=$ sprayed with $0.25 \mathrm{~mm}$ spermidine and in $75 \mathrm{~mm}$ salinealkaline solution. 


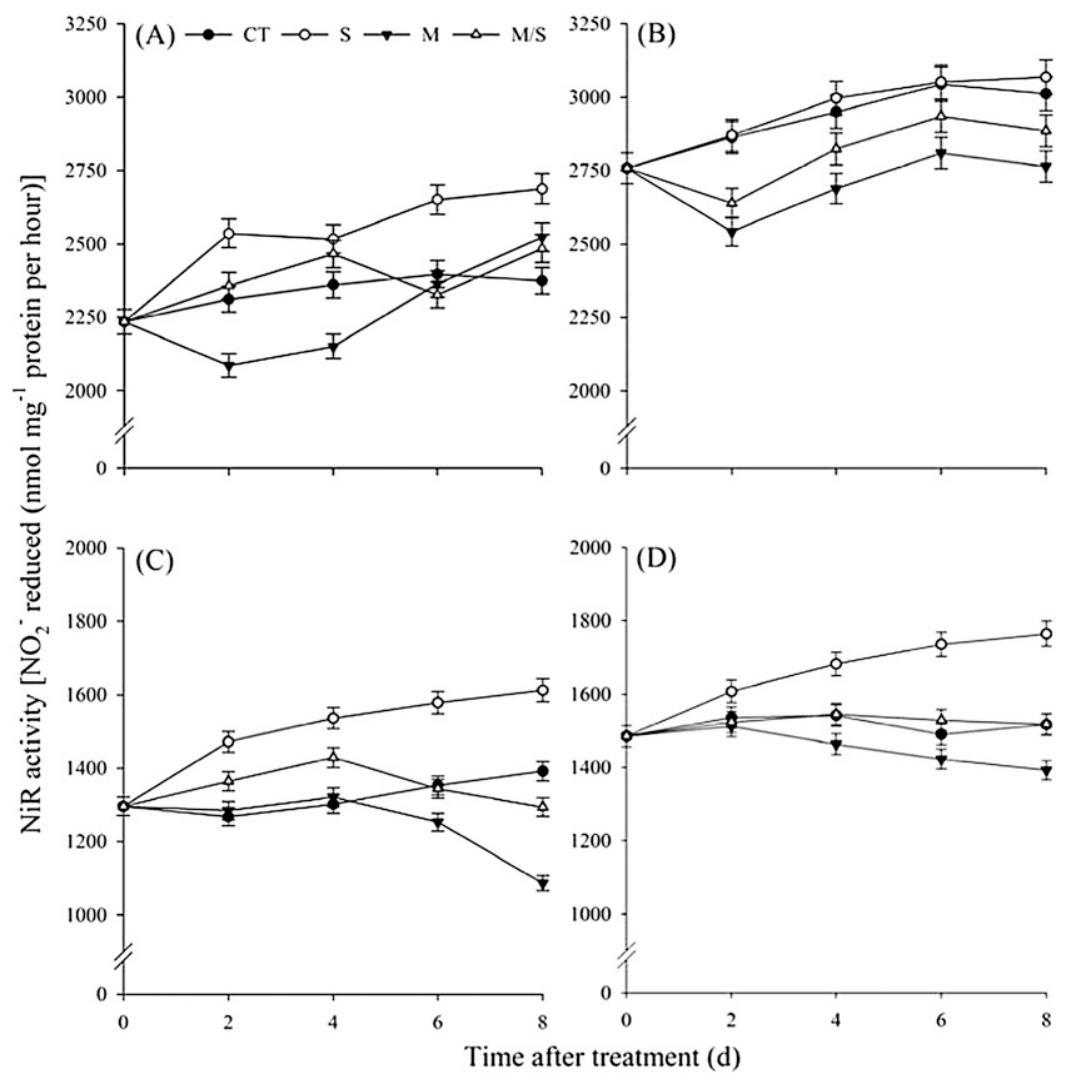

Fig. 6. Effects of exogenous spermidine on nitrite reductase (NiR) activities of tomato seedlings grown under salinityalkalinity combined stress: (A) 'Zhongza No. 9' leaves, (B) 'Jinpeng Chaoguan' leaves, (C) 'Zhongza No. 9' roots, (D) 'Jinpeng Chaoguan' roots. Data represent means $\pm \mathrm{SE}$; the vertical bars are the SES $(n=3) ; C T=$ in half-strength $(1 / 2)$ Hoagland solution, $\mathrm{M}=$ in $75 \mathrm{~mm}$ saline-alkaline solution (1 $\left.\mathrm{NaCl}: 9 \mathrm{Na}_{2} \mathrm{SO}_{4}: 9 \quad \mathrm{NaHCO}_{3}: 1 \quad \mathrm{Na}_{2} \mathrm{CO}_{3}\right), \mathrm{S}=$ sprayed with $0.25 \mathrm{~mm}$ spermidine and in $1 / 2$ Hoagland solution, $\mathrm{M} / \mathrm{S}=$ sprayed with $0.25 \mathrm{~mm}$ spermidine and in $75 \mathrm{~mm}$ saline-alkaline solution.

the same treatment. Finally, root GS activity was relatively low in comparison with that of leaf.

For NADH-GOGAT, both cultivars showed higher activity in roots than in leaves (Fig. 9). Leaf NADH-GOGAT activities in the single Spd treatment, especially for 'Zhongza No. 9' plants, gradually increased with time, whereas homologous enzyme activities in stressed plants were only slightly improved, by exogenous Spd, except for the significant rise in 'Zhongza No. 9' on Days 6 and $8(P<0.05)$. We also did not find any distinct differences in leaf NADH-GOGAT activity

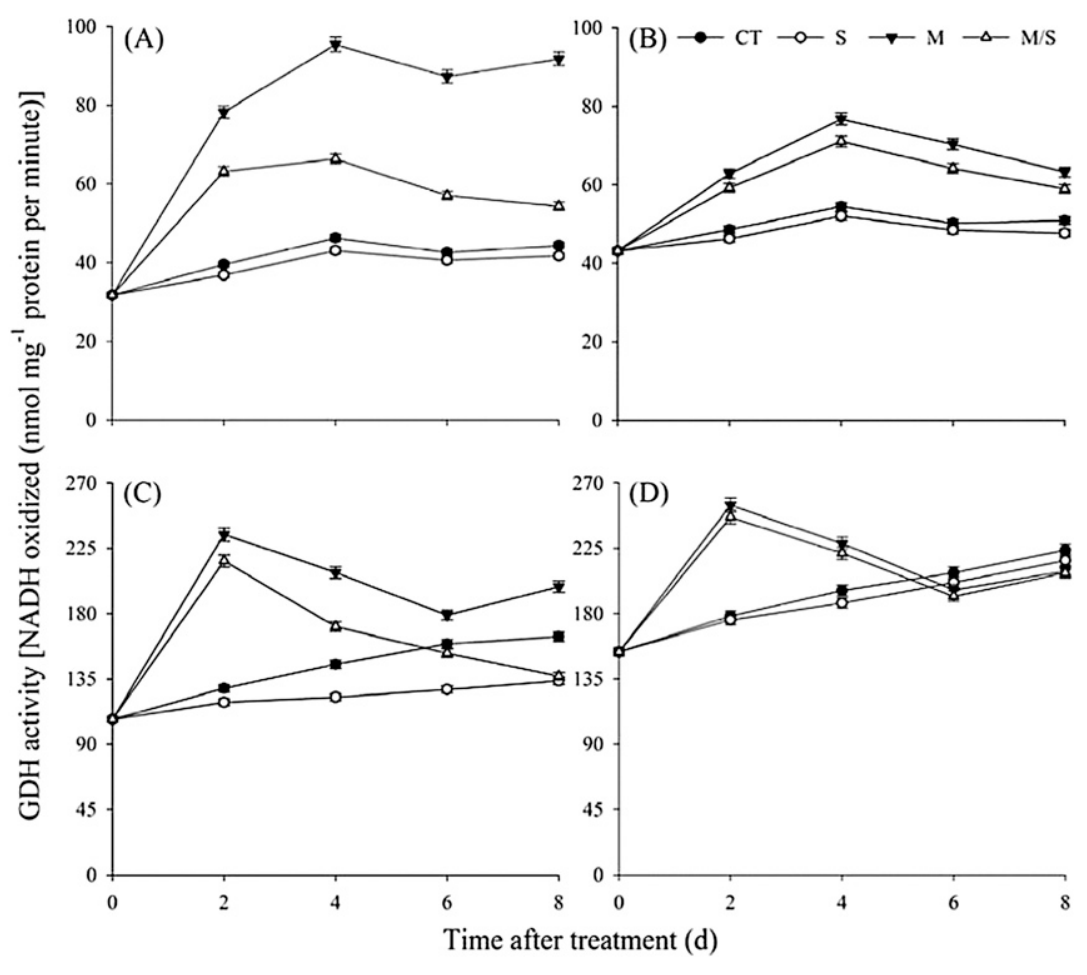

Fig. 7. Effects of exogenous spermidine on NADH-dependent glutamate dehydrogenase (NADH-GDH) activities of tomato seedlings grown under salinity-alkalinity combined stress: (A) 'Zhongza No. 9' leaves, (B) 'Jinpeng Chaoguan' leaves, (C) 'Zhongza No. 9' roots, (D) 'Jinpeng Chaoguan' roots. Data represent means $\pm \mathrm{SE}$; the vertical bars are the SES $(\mathrm{n}=3) ; \mathrm{CT}=$ in half-strength (1/2) Hoagland solution, $\mathrm{M}=$ in $75 \mathrm{~mm}$ saline-alkaline solution $\left(1 \mathrm{NaCl}: 9 \mathrm{Na}_{2} \mathrm{SO}_{4}: 9\right.$ $\mathrm{NaHCO}_{3}: 1 \mathrm{Na}_{2} \mathrm{CO}_{3}$ ), $\mathrm{S}=$ sprayed with $0.25 \mathrm{~mm}$ spermidine and in $1 / 2$ Hoagland solution, $\mathrm{M} / \mathrm{S}=$ sprayed with $0.25 \mathrm{~mm}$ spermidine and in $75 \mathrm{~mm}$ saline-alkaline solution. 


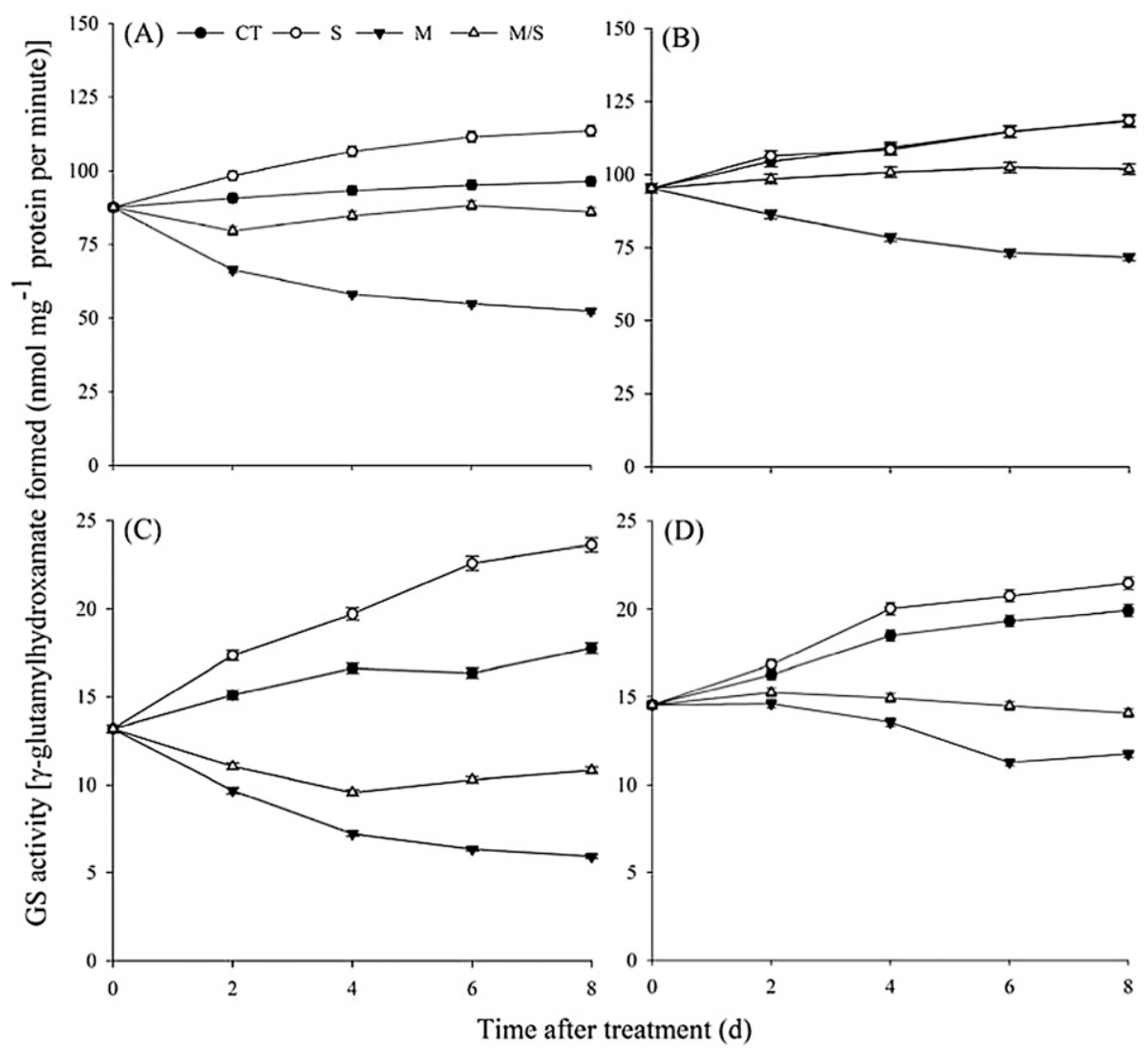

Fig. 8. Effects of exogenous spermidine on glutamine synthetase (GS) activities of tomato seedlings grown under salinity-alkalinity combined stress: (A) 'Zhongza No. 9' leaves, (B) 'Jinpeng Chaoguan' leaves, (C) 'Zhongza No. 9' roots, (D) 'Jinpeng Chaoguan' roots. Data represent means $\pm \mathrm{SE}$; the vertical bars are the SES $(\mathrm{n}=3)$; $\mathrm{CT}=$ in half-strength $(1 / 2)$ Hoagland solution, $\mathrm{M}=$ in $75 \mathrm{~mm}$ saline-alkaline solution $(1 \mathrm{NaCl}: 9$ $\left.\mathrm{Na}_{2} \mathrm{SO}_{4}: 9 \quad \mathrm{NaHCO}_{3}: 1 \quad \mathrm{Na}_{2} \mathrm{CO}_{3}\right), \mathrm{S}=$ sprayed with $0.25 \mathrm{~mm}$ spermidine and in $1 / 2$ Hoagland solution, $\mathrm{M} / \mathrm{S}=$ sprayed with $0.25 \mathrm{~mm}$ spermidine and in $75 \mathrm{~mm}$ saline-alkaline solution.

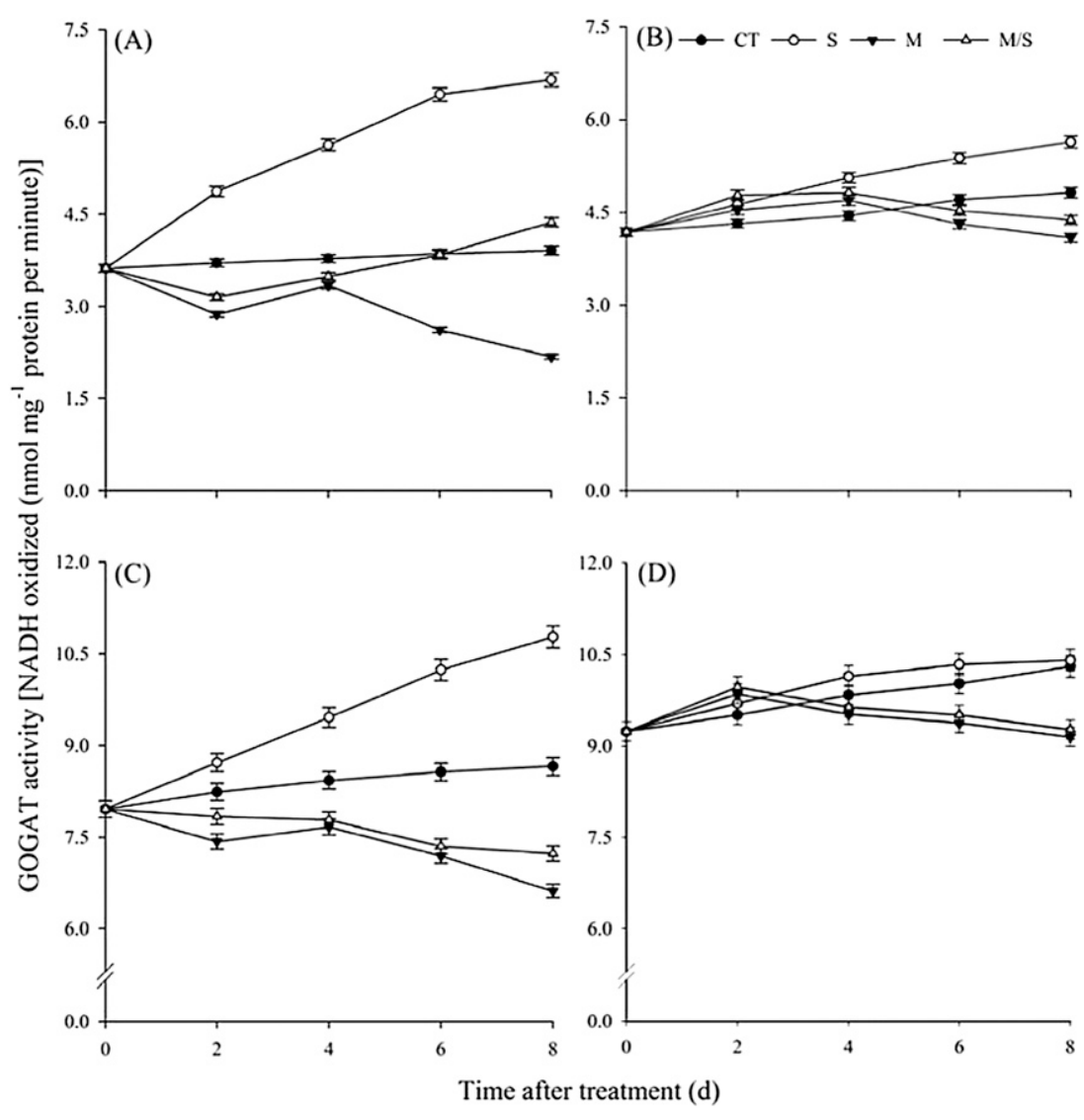

Fig. 9. Effects of exogenous spermidine on NADHdependent glutamate synthase (NADH-GOGAT) activities of tomato seedlings grown under salinity-alkalinity combined stress: (A) 'Zhongza No. 9' leaves, (B) 'Jinpeng Chaoguan' leaves, (C) 'Zhongza No. 9' roots, (D) 'Jinpeng Chaoguan' roots. Data represent means $\pm \mathrm{SE}$; the vertical bars are the SES $(\mathrm{n}=3)$; CT $=$ in half-strength $(1 / 2)$ Hoagland solution, $\mathrm{M}=$ in $75 \mathrm{~mm}$ saline-alkaline solution (1 NaCl:9 $\left.\mathrm{Na}_{2} \mathrm{SO}_{4}: 9 \quad \mathrm{NaHCO}_{3}: 1 \quad \mathrm{Na}_{2} \mathrm{CO}_{3}\right), \mathrm{S}=$ sprayed with $0.25 \mathrm{~mm}$ spermidine and in $1 / 2$ Hoagland solution, $\mathrm{M} / \mathrm{S}=$ sprayed with $0.25 \mathrm{~mm}$ spermidine and in $75 \mathrm{~mm}$ saline-alkaline solution. 
between control and stressed plants of 'Jinpeng Chaoguan'. Under stress conditions, root NADH-GOGAT activities of both cultivars, when compared with control, were significantly reduced $(P<0.05)$. Moreover, Spd showed insignificant amelioration in NADH-GOGAT activity, in all stressed plants, although exogenous Spd had significantly increased corresponding enzyme activity in unstressed roots of 'Zhongza No. 9' $(P<0.05)$, yet no obvious improvement to 'Jinpeng Chaoguan' normal roots was found.

ACTIVITIES OF GLUTAMATE OXALOACETATE TRANSAMINASE AND GLUTAMATE PYRUVATE TRANSAMinASE. In both leaves and roots of the two cultivars, salinity-alkalinity mixed stress led to a significant decrease in GOT activity $[P<0.05$ (Fig. 10)]. After spraying Spd, leaf GOT activities were all significantly elevated, especially for the stressed plants of 'Jinpeng Chaoguan'. Furthermore, all Spd and salinity-alkalinity-treated plants of 'Zhongza No. 9' had leaf GOT activities that increased early and declined later with peak values on Day 4 after treatment, whereas the homologous leaf enzyme activities of 'Jinpeng Chaoguan' simply increased over time. By contrast, we found less difference between the root GOT activities of 'Zhongza No. 9' plants, treated with and without Spd, and nearly no difference in the corresponding enzyme activities of 'Jinpeng Chaoguan' roots.

As described in GOT, salinity-alkalinity stress caused a significant reduction in the GPT activities of both cultivars as compared with control $(P<0.05)$. Meanwhile, GPT activities of 'Zhongza No. 9' were lower than those of 'Jinpeng Chaoguan' under the same conditions (Fig. 11). With application of Spd, leaf GPT activities were differentially enhanced, especially for the non-stressed plants of 'Zhongza No. 9', which reached marked levels. For the stressed plants of 'Jinpeng Chaoguan', corresponding leaf enzyme activities increased early and decreased later, whether Spd was used or not. The remaining leaf GPT activities of two cultivars either steadily or slightly changed with time. In the roots of 'Jinpeng Chaoguan' plants supplemented with Spd, the GPT activities were almost unchanged, whereas they increased significantly in 'Zhongza No. 9' $(P<0.05)$. Stressed plants displayed more GPT activity when seedlings were treated with Spd.

\section{Discussion}

Salt stress is a widespread environmental problem that has caused detrimental effects on plant growth and productivity (Galvez et al., 2012). Previous studies focused on neutral salt stress, and limited attention has been given to saline-alkaline mixed stress despite salinization and alkalinization frequently co-occurring in nature (Wang et al., 2011). Based on published test results, polamines have important function in alleviating adverse effects from salt stress, although their actual function remains controversial (Roychoudhury et al., 2011). Moreover, much research shows that the response of $\mathrm{N}$ metabolism in plants to salt stress is complicated and sensitive (Debouba et al., 2006; Flores et al., 2004; Surabhi et al., 2008). We, therefore, investigated the effects of exogenous Spd on plant growth and $\mathrm{N}$ metabolism in tomato seedlings with salinity-alkalinity mixed stress.

Suppressed plant growth is one of the most obvious results of salt stress (Duan et al., 2008). We found that salinity-alkalinity mixed stress has a significant and negative effect on almost all of the growth parameters assayed in this experiment (Table 1), especially on the root/ shoot dry weight ratio and root and shoot dry weights. Under salinityalkalinity stress, for the Spd-treated plants of 'Zhongza No. 9', we saw notable increases in plant height, root fresh weight, and shoot dry weight; however, we found fewer differences in 'Jinpeng Chaoguan'. These results indicate that exogenous Spd may mitigate the salinityalkalinity-mediated growth inhibition of plants to some extent, especially in 'Zhongza No. 9', which is more salt-sensitive. Effects of applied Spd in our experiment were similar to those described in cucumber [Cucumis sativus cv. Jinchun No. 2 (Du et al., 2007)] and rice [Oryza sativa cv. M-1-48 (Roychoudhury et al., 2011)].

Protein synthesis in plants can be regulated by salt stress. Most soluble proteins are enzymes that participate in various metabolisms of plants; therefore, soluble protein

Fig. 10. Effects of exogenous spermidine on glutamate oxaloacetate transaminase (GOT) activities of tomato seedlings grown under salinity-alkalinity combined stress: (A) 'Zhongza No. 9' leaves, (B) 'Jinpeng Chaoguan' leaves, (C) 'Zhongza No. 9' roots, (D) 'Jinpeng Chaoguan' roots. Data represent means $\pm \mathrm{SE}$; the vertical bars are the SES $(\mathrm{n}=3)$; $\mathrm{CT}=$ in half-strength $(1 / 2)$ Hoagland solution, $\mathrm{M}=$ in $75 \mathrm{~mm}$ saline-alkaline solution $(1 \mathrm{NaCl}: 9$ $\left.\mathrm{Na}_{2} \mathrm{SO}_{4}: 9 \mathrm{NaHCO}_{3}: 1 \mathrm{Na}_{2} \mathrm{CO}_{3}\right), \mathrm{S}=$ sprayed with $0.25 \mathrm{~mm}$ spermidine and in $1 / 2$ Hoagland solution, $\mathrm{M} / \mathrm{S}=$ sprayed with $0.25 \mathrm{~mm}$ spermidine and in $75 \mathrm{~mm}$ saline-alkaline solution. 


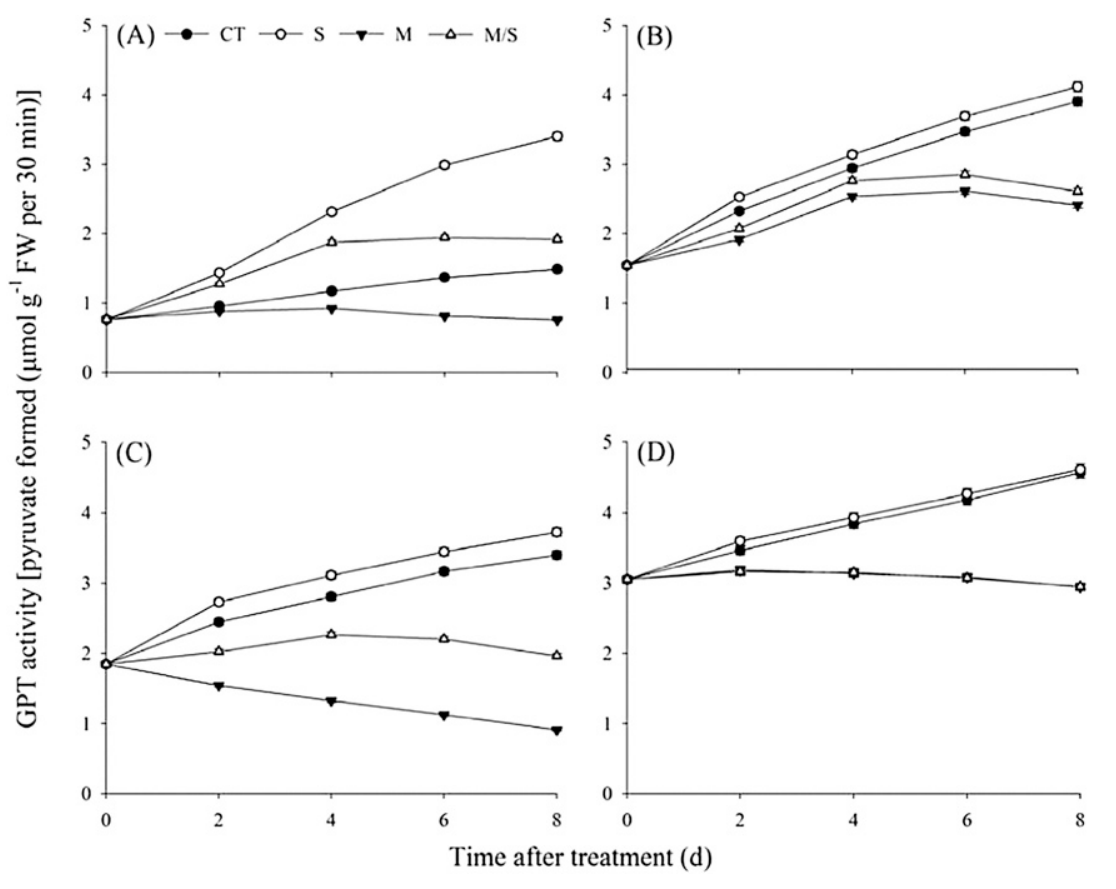

Fig. 11. Effects of exogenous spermidine on glutamate pyruvate transaminase (GPT) activities of tomato seedlings grown under salinity-alkalinity combined stress: (A) 'Zhongza No. 9' leaves, (B) 'Jinpeng Chaoguan' leaves, (C) 'Zhongza No. 9' roots, (D) 'Jinpeng Chaoguan' roots. Data represent means \pm SE; the vertical bars are the SES $(\mathrm{n}=3) ; \mathrm{CT}=$ in half-strength $(1 / 2)$ Hoagland solution, $\mathrm{M}=$ in $75 \mathrm{~mm}$ saline-alkaline solution $(1 \mathrm{NaCl}: 9$ $\mathrm{Na}_{2} \mathrm{SO}_{4}: 9 \mathrm{NaHCO}_{3}: 1 \mathrm{Na}_{2} \mathrm{CO}_{3}$ ), $\mathrm{S}=$ sprayed with $0.25 \mathrm{~mm}$ spermidine and in $1 / 2$ Hoagland solution, $\mathrm{M} / \mathrm{S}=$ sprayed with $0.25 \mathrm{~mm}$ spermidine and in $75 \mathrm{~mm}$ saline-alkaline solution.

content is considered one of the most important indices reflecting the overall metabolic level in plants (Doganlar et al., 2010). In the present work, salinity-alkalinity mixed stress caused significant reductions in soluble protein contents of both leaf and root, as compared with the control, whereas exogenous Spd showed the opposite facilitation effects, especially for stressed 'Zhongza No. 9' seedlings (Fig. 1). This may indicate that protein synthesis in tomato plants was inhibited by saline-alkaline stress. The high content of soluble protein can help maintain a relatively low $\psi_{\mathrm{S}}$ in plant cells and further alleviate damages that result from salt stress (Du et al., 2007). Exogenous Spd treatment could help produce new induced proteins and/or accelerate the synthesis process of some original proteins and, thus, adjust $\psi_{\mathrm{S}}$ of cells to keep a certain turgor and further to ensure the normal proceeding of a series of physiological and biochemical processes under stress conditions (Li et al., 2010b).

Salt stress is also known to affect the free amino acid contents in plants (Surabhi et al., 2008). Salt-induced changes in free amino acid content may imply metabolic alterations from either resistance or sensitivity to salinity (Ferreira-Silva et al., 2010). In our study, the free amino acid levels in salinealkaline-stressed roots of both tomato cultivars all increased early and decreased later. At the same time, we found that the free amino acid contents in 'Zhongza No. 9' leaves sprayed with Spd were notably greater (Fig. 2A). Furthermore, the maximum levels of free amino acids in saline-alkaline-stressed roots of 'Zhongza No. 9' occurred on Day 4 after treatment, whereas the peak value was postponed to Day 6 when exogenous Spd was applied (Fig. 2C). Nonetheless, Spd had little effect on the peak time of free amino acids in roots of 'Jinpeng Chaoguan' (Fig. 2D). The adaptive significance of free amino acid variation, during exogenous Spd and salinity-alkalinity mixed stress treatment, possibly as a result of its functions in adjusting internal osmotic conditions and destroying free radicals formed in plants from abiotic stressors (Amin et al., 2011).

Nitrogen is an integral part of proteins, nucleic acids, and other important cellular parts, and it determines the level of growth and development in plants. The $\mathrm{N}$ status of a plant is often measured by its composition of the different $\mathrm{N}$ molecules and various, related metabolic enzymes (Gangwar and Singh, 2011). When stressed with saline-alkaline, the $\mathrm{NO}_{3}{ }^{-}-\mathrm{N}$ contents of leaf and root, of both tomato cultivars, were reduced to minimums on Days 2 (Fig. 3A-B) and 4 (Fig. 3C-D), respectively, whereas the peak values of $\mathrm{NH}_{4}{ }^{+}-\mathrm{N}$ levels in leaf and root turned up on Days 4 (Fig. 4A-B) and 2 (Fig. 4C-D), respectively. At the same time, the leaf NR activities in stressed plants were depressed at first and then increased to some degree (Fig. 5A-B), but we observed relatively little changes in root NR, except for its initial decline (Fig. 5CD). The variation of leaf NiR in stressed seedlings (Fig. 6A-B) was similar to corresponding leaf NR, although root NiR activities decreased with increasing time of stress treatment (Fig. 6C-D). Salt stress can diminish the uptake of $\mathrm{NO}_{3}{ }^{-}-\mathrm{N}$ in a plant (Debouba et al., 2006). Our study confirms that the reduction of $\mathrm{NO}_{3}{ }^{-} \mathrm{N}$ and, therefore, the inhibition of NR and $\mathrm{NiR}$ activity could be the initial result of a series of injuries caused by high salinity-alkalinity. The $\mathrm{NO}_{3}{ }^{-}-\mathrm{N}$ decrease from the saline-alkaline treatment may be attributed to an uptake competition between $\mathrm{NO}_{3}{ }^{-}$and other existing anions such as $\mathrm{Cl}^{-}, \mathrm{SO}_{4}{ }^{2-}, \mathrm{CO}_{3}{ }^{2-}$, and $\mathrm{HCO}_{3}{ }^{-}$, which may have unfavorable influences on plasma membrane permeability (Wang et al., 2011). Similar to $\mathrm{NO}_{3}{ }^{-} \mathrm{N}$ changes, the contents of $\mathrm{NH}_{4}{ }^{+}-\mathrm{N}$ initially increased and then decreased, perhaps from aggravated ion toxicity, imbalance of osmotic regulation, and/or N metabolic disturbance from the salinity-alkalinity stress. To minimize toxicity of excess $\mathrm{NH}_{4}^{+}$(Wang et al., 2007; Zhang et al., 2006), the reduction reaction of $\mathrm{NO}_{3}{ }^{-}-\mathrm{N}$ to $\mathrm{NH}_{4}{ }^{+}-\mathrm{N}$ was restrained by weakening $\mathrm{NR}$ and $\mathrm{NiR}$ activities, by diminishing $\mathrm{NO}_{3}{ }^{-} \mathrm{-}$ uptake, and/or by rapid assimilation of $\mathrm{NH}_{4}{ }^{+}$stimulated through the NADH-GDH and GS/NADH-GOGAT pathways.

In our experiment, a stress-induced increase in plant NADH$\mathrm{GDH}$, which is an important enzyme that is involved in $\mathrm{N}$ utilization and conversion, occurred under the saline-alkaline condition despite being followed by either a fluctuation or a notable decrease after its peak value (Fig. 7). Enhanced NADH-GDH activity can be used to catalyze the reversible reaction of glutamate from $\mathrm{NH}_{4}{ }^{+}-\mathrm{N}$ (Skopelitis et al., 2006) because the ammonium formed by successive action of NR and $\mathrm{NiR}$ is harmful to cells and needs to be quickly assimilated. Similar changes of NADH-GDH, in response to salt stress, are 
also reported for mulberry [Morus alba cv. ATP (Ramanjulu et al., 1994)], wheat [Triticum aestivum cv. Yumai 34 (Wang et al., 2007)], and rice [cv. I Kong Pao (Lutts et al., 1999)]. Later decrease of NADH-GDH, however, may be the result of its uncertain dual character (Huang and Tian, 2001), the complexity of saline-alkaline mixed stress (Wang et al., 2011), and/or the alternative competition and synergetic effects of GS/ NADH-GOGAT, which is considered the main pathway for the assimilation of $\mathrm{NH}_{4}{ }^{+}$(Surabhi et al., 2008). The first step in the GS/NADH-GOGAT cycle is catalyzed by GS, which converts ammonium to glutamine, followed by the transformation of glutamine into glutamate by the NADH-GOGAT reaction (Zilli et al., 2008). Our results show that: 1) levels of GS and NADH-GOGAT are lowered by the stress of salinity-alkalinity; 2) GS activity is lower in root than leaf (Fig. 8); and 3) GOGAT activity is higher in root than leaf (Fig. 9). Based on our analyses, reduction of GS and NADH-GOGAT activities may be associated with enhanced NADH-GDH. The reduction could also be attributed to stress-induced, oxidative modifications of these enzymatic proteins (Gangwar and Singh, 2011). Other reports, however, show increased GS and GOGAT activities in response to saline conditions (Surabhi et al., 2008); however, the adaptive significance of the elevated enzyme activity is still unclear despite the possibility that GS/NADH-GOGAT may facilitate the production of glutamine, proline, and other regulatory substances that promote osmotic and $\mathrm{pH}$ adjustments under stressed conditions (Lorenzo et al., 2001). Changes in the activity of the $\mathrm{NH}_{4}{ }^{+}$assimilation enzyme may differ by plant species, cultivar, growth stage, tissue, duration and intensity of treatment, and so on.

All factors that influence uptake and transformation of $\mathrm{N}$ can affect the normal growth and development of plants (MuroPastor and Florencio, 2003). Transamination reactions, which transfer amino groups from glutamate to other amino acids, are important to plant $\mathrm{N}$ metabolism because they are closely associated with the flow of $\mathrm{N}$ from the amino and amide groups, both of which are essential for plant growth (Seebauer et al., 2004). As the most active aminotransferases, GOT and GPT catalyze different reactions that produce aspartate and alanine, respectively (Liang et al., 2011). In this study, we found notable stress-induced decreases in GOT and GPT activities in both leaves and roots of the two varieties. Except for a gradual increase in the leaf GPT of 'Jinpeng Chaoguan', other leaf GOT and GPT activities in saline-alkaline-stressed plants have changed little over time. Moreover, the GOT and GPT activities in stressed roots of both cultivars gradually decreased with passing time, and 'Zhongza No. 9' had larger variation (Figs. 10 and 11). Under the stress, activities of GOT and GPT reduced, which could actually be caused by the weakened GS/NADHGOGAT pathway, because glutamate is the first amino acid synthesized from inorganic $\mathrm{N}$ taken up by plants (Liang et al., 2011) and mainly derived from $\mathrm{NH}_{4}{ }^{+}$assimilation catalyzed by GS and NADH-GOGAT (Gangwar and Singh, 2011). In the presence of high $\mathrm{NH}_{4}{ }^{+}-\mathrm{N}$, the interregulation of transamination, mediated by GOT and GPT, may induce $\mathrm{NH}_{4}{ }^{+}$assimilation systems such as the GS/NADH-GOGAT cycle and other amino group transfer reactions to alleviate the toxic effects of accumulated $\mathrm{NH}_{4}{ }^{+}$and even $\mathrm{N}$ metabolic disorders.

Polyamines, the ubiquitous and vital physiological effectors in plant cells, could provide protection against a broad spectrum of abiotic stresses, including salt stress. Besides scavenging for free radicals, exogenous Spd may also help prevent electrolyte and/or amino acid leakage and repair plasma membrane damage, all in plants subjected to salinity (Roychoudhury et al., 2011). Our results indicate that exogenous Spd could prevent stress-induced increases in $\mathrm{NH}_{4}{ }^{+}-\mathrm{N}$ levels and NADH-GDH activity as well as prevent decreases in $\mathrm{NO}_{3}{ }^{-}-\mathrm{N}$ content and $\mathrm{NR}$, NiR, GS, NADH-GOGAT, GOT, and GPT activities, all in plants under saline-alkaline mixed stress. This may be possible as a result of the multiple protective roles of Spd, which is considered an important signaling regulator in stress signal transmission and which can be integrated with ionic channels and negatively charged biomacromolecules such as membrane phospholipids, acidic proteins, nucleic acids, and cell wall components (Kusano et al., 2008; Zhang et al., 2006). As a result, $\mathrm{NH}_{4}{ }^{+}$and its related enzymes may tend to be in proper and balanced states, in vivo, enabling stress-induced damage mitigation. Some differences in the functions of Spd among cultivars of a given species exist. However, based on our observations, exogenous Spd improves stressed plants more than a control, especially in 'Zhongza No. 9'.

Tomato is a moderately salt-tolerant species. Nevertheless, salinity-alkalinity mixed stress, in this study, inhibited plant growth and increased accumulation of ammonium in both Jinpeng Chaoguan and Zhongza No. 9 cultivars, whereas foliar spraying of $0.25 \mathrm{~mm}$ Spd partially counteracted the deleterious effects of the saline-alkaline stress. From the results of this experiment, we concluded that exogenous Spd applied to tomato plants reduces stress-induced increases in free amino acids, $\mathrm{NH}_{4}{ }^{+}-\mathrm{N}$ contents, and NADH-GDH activities, while reducing saline-alkaline-mediated inhibition of soluble protein, $\mathrm{NO}_{3}{ }^{-}-\mathrm{N}$ levels; and NR, NiR, GS, NADH-GOGAT, GOT, and GPT activities promote plant growth, especially for 'Zhongza No. 9'. The positive effects of exogenous Spd on plant $\mathrm{N}$ metabolism may also include further alleviation of salinealkaline-resulted injuries. Exogenous Spd, therefore, could be used as a growth-regulating substance to maintain plant survival under salinity-alkalinity mixed stress. The effects of exogenous Spd on saline-alkaline toxicity, however, may depend on the plant species, and even cultivars, as a result of complexity and diversity of resistance mechanisms of different plants. To better understand the specific role of exogenous Spd on plants exposed to saline-alkaline conditions, further research is needed in this area.

\section{Literature Cited}

Alcazar, R., F. Marco, J.C. Cuevas, M. Patron, A. Ferrando, P. Carrasco, A.F. Tiburcio, and T. Altabella. 2006. Involvement of polyamines in plant response to abiotic stress. Biotechnol. Lett. 28:1867-1876.

Amin, A.A., F.A.E. Gharib, M. El-Awadi, and M.R. El-Sherbeny. 2011. Physiological response of onion plants to foliar application of putrescine and glutamine. Sci. Hort. 129:353-360.

Bradford, M.M. 1976. A rapid and sensitive method for the quantitation of microgram quantities of protein utilizing the principle of protein-dye binding. Anal. Biochem. 72:248-254.

Cataldo, D.A., M. Haroon, L.E. Schrader, and V.L. Youngs. 1975. Rapid colorimetric determination of nitrate in plant tissue by nitration of salicylic acid. Commun. Soil Sci. Plant 6:71-80.

Chattopadhayay, M.K., B.S. Tiwari, G. Chattopadhyay, A. Bose, D.N. Sengupta, and B. Ghosh. 2002. Protective role of exogenous polyamines on salinity-stressed rice (Oryza sativa) plants. Physiol. Plant. 116:192-199.

Debouba, M., H. Gouia, A. Suzuki, and M.H. Ghorbel. 2006. NaCl stress effects on enzymes involved in nitrogen assimilation pathway 
in tomato Lycopersicon esculentum seedlings. J. Plant Physiol. 163:1247-1258.

Doganlar, Z.B., K. Demir, H. Basak, and I. Gul. 2010. Effects of salt stress on pigment and total soluble protein contents of three different tomato cultivars. African J. Agr. Res. 5:2056-2065.

Du, C.X., J. Li, S.R. Guo, and H.F. Fan. 2007. Effects of exogenous spermidine on the growth and soluble protein expression in cucumber seedlings under $\mathrm{NaCl}$ stress. Acta Botanica Boreal-Occident Sinica 27:1179-1184 [in Chinese].

Duan, J.J., J. Li, S.R. Guo, and Y.Y. Kang. 2008. Exogenous spermidine affects polyamine metabolism in salinity-stressed Cucumis staves roots and enhances short-term salinity tolerance. J. Plant Physiol. 165:1620-1635.

Ferreira-Silva, S.L., E.N. Silva, F.E.L. Carvalho, C.S. de Lima, F.A.L. Alves, and J.A.G. Silveira. 2010. Physiological alterations modulated by rootstock and scion combination in cashew under salinity. Sci. Hort. 127:39-45.

Flores, P., M.A. Botella, A. Cerda, and V. Martinez. 2004. Influence of nitrate level on nitrate assimilation in tomato (Lycopersicon esculentum) plants under saline stress. Can. J. Bot. 82:207-213.

Galvez, F.J., M. Baghour, G. Hao, O. Cagnac, M.P. RodriguezRosales, and K. Venema. 2012. Expression of LeNHX isoforms in response to salt stress in salt sensitive and salt tolerant tomato species. Plant Physiol. Biochem. 51:109-115.

Gangwar, S. and V.P. Singh. 2011. Indole acetic acid differently changes growth and nitrogen metabolism in Pisum sativum L. seedlings under chromium (VI) phytotoxicity: Implication of oxidative stress. Sci. Hort. 129:321-328.

Groppa, M.D. and M.P. Benavides. 2008. Polyamines and abiotic stress: Recent advances. Amino Acids 34:35-45.

Hu, X.H., Y. Zhang, Y. Shi, Z. Zhang, Z.R. Zou, H. Zhang, and J.Z. Zhao. 2012. Effect of exogenous spermidine on polyamine content and metabolism in tomato exposed to salinity-alkalinity mixed stress. Plant Physiol. Biochem. 57:200-209.

Huang, G.C. and B. Tian. 2001. The physiological role of glutamate dehydrogenase in higher plants. Chinese Bul. Bot. 18. 396-401 [in Chinese].

Kingsbury, R.W., E. Epstein, and R.W. Peary. 1984. Physiological responses to salinity in selected lines of wheat. Plant Physiol. 74:417-423.

Krom, M.D. 1980. Spectrophotometric determination of ammonia: A study of a modified Berthelot reaction using salicylate and dichloroisocyanurate. Analyst (Lond.) 105:305-316.

Kusano, T., T. Berberich, C. Tateda, and Y. Takahashi. 2008. Polyamines: Essential factors for growth and survival. Planta 228:367-381.

Li, R., F. Shi, and K. Fukuda. 2010a. Interactive effects of various salt and alkali stresses on growth, organic solutes, and cation accumulation in a halophyte Spartina alterniflora (Poaceae). Environ. Exp. Bot. 68:66-74.

Li, D.X., C.D. Li, H.C. Sun, W.X. Wang, L.T. Liu, and Y.J. Zhang. $2010 \mathrm{~b}$. Effects of drought on soluble protein content and protective enzyme system in cotton leaves. Front. Agr. China 4:56-62.

Liang, C.G., L.P. Chen, Y. Wang, J. Liu, G.L. Xu, and T. Li. 2011. High temperature at grain-filling stage affects nitrogen metabolism enzyme activities in grains and grain nutritional quality in rice. Rice Sci. 18:210-216.
Lillo, C. 1984. Diurnal variations of nitrite reductase, glutamine synthetase, glutamate synthase, alanine aminotransferase and aspartate aminotransferase in barley leaves. Physiol. Plant. 61:214-218.

Lorenzo, H., J.M. Siverio, and M. Caballero. 2001. Salinity and nitrogen fertilization and nitrogen metabolism in rose plants. J. Agr. Sci. 137:77-84.

Lutts, S., V. Majerus, and J.M. Kinet. 1999. NaCl effects on proline metabolism in rice (Oryza sativa) seedlings. Physiol. Plant. 105:450 458.

Maathuis, F.J. 2009. Physiological functions of mineral macronutrients. Curr. Opin. Plant Biol. 12:250-258.

Muro-Pastor, M.I. and F.J. Florencio. 2003. Regulation of ammonium assimilation in cyanobacteria. Plant Physiol. Biochem. 41:595-603.

Ramanjulu, S., K. Veeranjaneyulu, and C. Sudhakar. 1994. Short-term shifts in nitrogen metabolism in mulberry (Morus alba L.) under salt shock. Phytochemistry 37:991-995.

Roychoudhury, A., S. Basu, and D.N. Sengupta. 2011. Amelioration of salinity stress by exogenously applied spermidine or spermine in three varieties of indica rice differing in their level of salt tolerance. J. Plant Physiol. 168:317-328.

Seebauer, J.R., S.P. Moose, B.J. Fabbri, L.D. Crossland, and F.E. Below. 2004. Amino acid metabolism in maize earshoots: Implications for assimilate preconditioning and nitrogen signaling. Plant Physiol. 136:4326-4334.

Skopelitis, D.S., N.V. Paranychianakis, and K.A. Paschalidis. 2006. Abiotic stress generates ROS that signal expression of anionic glutamate dehydrogenases to form glutamate for proline synthesis in tobacco and grapevine. Plant Cell 18:2767-2781.

Surabhi, G.K., A.M. Reddy, G.J. Kumari, and C. Sudhakar. 2008. Modulations in key enzymes of nitrogen metabolism in two high yielding genotypes of mulberry (Morus alba L.) with differential sensitivity to salt stress. Environ. Exp. Bot. 64:171-179.

Wang, X.P., S.J. Geng, Y.J. Ri, D.H. Cao, J. Liu, D.C. Shi, and C.W. Yang. 2011. Physiological responses and adaptive strategies of tomato plants to salt and alkali stresses. Sci. Hort. 130:248-255.

Wang, Z.Q., Y.Z. Yuan, J.Q. Ou, Q.H. Lin, and C.F. Zhang. 2007. Glutamine synthetase and glutamate dehydrogenase contribute differentially to proline accumulation in leaves of wheat (Triticum aestivum) seedlings exposed to different salinity. J. Plant Physiol. 164:695-701.

Yemm, E.W. and E.C. Cocking. 1955. The determination of aminoacids with ninhydrin. Analyst (Lond.) 80:209-213.

Zhang, R.H., S.R. Guo, and H.F. Fan. 2006. Effects of exogenous Spd on $\mathrm{NO}_{3}{ }^{-} \mathrm{N}, \mathrm{NH}_{4}{ }^{-} \mathrm{N}$ contents and nitrate reductase activity of salt stressed leaves and roots of cucumber seedlings. J. Wuhan Bot. Res. 24:381-384 [in Chinese].

Zilli, C.G., K.B. Balestrasse, G.G. Yannarelli, A.H. Polizio, D.M. Santa-Cruz, and M.L. Tomaro. 2008. Heme oxygenase up-regulation under salt stress protects nitrogen metabolism in nodules of soybean plants. Environ. Exp. Bot. 64:83-89.

Zushi, K. and N. Matsuzoe. 2009. Seasonal and cultivar differences in salt-induced changes in antioxidant system in tomato. Sci. Hort. 120:181-187. 